\title{
Toxicity of bisphenol A and its structural congeners to microalgae Chlorella vulgaris and Desmodesmus armatus
}

\author{
Karolina Czarny-Krzymińska $^{1}$ (D) - Barbara Krawczyk ${ }^{1}$ (D) · Dominik Szczukocki ${ }^{1}$ D
}

Received: 1 October 2021 / Revised and accepted: 18 January 2022 / Published online: 5 February 2022

(c) The Author(s) 2022

\begin{abstract}
Bisphenol A and its structural congeners are increasingly recognized as emerging contaminants with toxic and estrogenic potential that have been widely used in many consumer products. Due to their widespread occurrence in aquatic environment, they could pose risks to the primary producers, such as microalgae. Therefore, the objective of this study was to examine the toxicity of bisphenol A, its six structural congeners, and their mixture towards the green algae Chlorella vulgaris and Desmodesmus armatus. Bisphenol A (average 14 days, $\mathrm{EC}_{50}: 42.29 \mathrm{mg} \mathrm{L}^{-1}$ ) exhibited less harmful effect than structural congeners, such as bisphenol AF, bisphenol G, bisphenol X for C. vulgaris (average 14 days, $\mathrm{EC}_{50}: 22.39 \mathrm{mg} \mathrm{L}^{-1}$ ) and bisphenol AF, bisphenol G, bisphenol M, bisphenol X for D. armatus (average 14 days, $\mathrm{EC}_{50}: 27.16 \mathrm{mg} \mathrm{L}^{-1}$ ), respectively. Moreover, exposure to combined bisphenol A and its structural congeners leads to synergistic effects. Thus, the increased adverse effect caused by complex chemical mixture poses a greater risk to microalgae. The order of toxic effect (14 days, $\mathrm{EC}_{50}$ ) of individual and combined structural congeners was: bisphenol $\mathrm{G}>$ bisphenol $\mathrm{X}>$ mixture $>$ bisphenol $\mathrm{AF}>$ bisphenol $\mathrm{A}>$ bisphenol $\mathrm{Y}>$ bisphenol $\mathrm{M}>$ bisphenol $\mathrm{P}$ for $C$. vulgaris and mixture $>$ bisphenol $\mathrm{G}>$ bisphenol $\mathrm{X}>$ bisphenol $\mathrm{M}>$ bisphenol AF $>$ bisphenol A $>$ bisphenol $\mathrm{Y}>$ bisphenol $\mathrm{P}$ for D. armatus, respectively. This is the first time that the toxicity of structural congeners of bisphenol A and its mixture to microalgae is described. Furthermore, these results were conducted to assess potential ecological risk of these compounds in the aquatic environment.
\end{abstract}

Keywords Chlorella vulgaris $\cdot$ Desmodesmus armatus $\cdot$ Chlorophyta $\cdot$ Bisphenol A $\cdot$ Structural congeners $\cdot$ Toxic effects

\section{Introduction}

Bisphenol A (BPA), a synthetic chemical substance belonging to phenols, has been widely used for more than 50 years as an additive or monomer in the manufacture of polycarbonate plastics, thermal paper, and epoxy resins in a wide range of consumer products, such as the lining of food cans, printing inks, compact discs, flame retardants, plastic bottles, thermal receipts, toys, pesticides, automobile parts, electronic and medical equipment (Makowska et al. 2021; Mustieles et al. 2021; Ramirez et al. 2021). To date, BPA is one of the world's highest volume-produced chemical compounds. Global production of this endocrine-disrupting compound reached 7.7 million tonnes in 2015 and is

Karolina Czarny-Krzymińska

karolina.czarny@chemia.uni.lodz.pl

1 Department of Inorganic and Analytical Chemistry, Faculty of Chemistry, Laboratory of Environmental Threats, University of Lodz, Tamka 12, 91-403 Lodz, Poland expected to exceed 10.6 million in 2022 (Bousoumah et al. 2021; Catenza et al. 2021; Ohore and Zhang 2021). Due to the widespread use of BPA in many consumer products, it can migrate into the environment mainly through leaching from BPA-based materials (Bhatnagar and Anastopoulos 2017; Bjornsdotter et al. 2017). Consequently, BPA has been detected in different environmental media such as surface water (0.04-8300 ng L ${ }^{-1}$ (Huang et al. 2012)), ground water (51-207 ng L ${ }^{-1}$ (Huang et al. 2012)), tap water (15-63 ng $\mathrm{L}^{-1}$ (Shao et al. 2008)), wastewater treatment plant effluents (10-1080 $\mathrm{ng} \mathrm{L}^{-1}$ (Lee and Part 2000)), wastewater treatment plant influents (193-2440 $\mathrm{ng} \mathrm{L}^{-1}$ (Drewes et al. 2005)), industrial effluents (220-370000 ng L ${ }^{-1}$ (Lee and Part 2000; Fukazawa et al. 2001)), sediment (329-10500 ng L ${ }^{-1}$ (Lin et al. 2006)), and air (1-17400 $\mathrm{pg} \mathrm{m}^{-3}$ (Fu and Kawamura 2010)).

Previous studies have reported that BPA was toxic to the aquatic organisms and can cause endocrine-disrupting effects, which are potentially associated with a variety of negative health consequences including developmental 
(Liang et al. 2021; Wang et al. 2021), reproductive (Faheem and Bhandari 2021), immunological (Li et al. 2018), and metabolic (Biemann et al. 2021) system disorders. Thus, in 2017, this endocrine-disrupting compound was included in the candidate list of Substances of Very High Concern (SVHC) and classified as toxic to reproduction by the European Chemical Agency (ECHA, 2017). Due to the increasing concern about the harmful effects of BPA exposure in living organisms and its ubiquity in the environment, several countries like the USA, China, Japan, Canada, and the European Union have enacted law regulations aiming to reduce the use of BPA in some consumer products (Frankowski et al. 2020; Catenza et al. 2021; Liu et al. 2021). For instance, its use was restricted in thermal paper since 2020 (less than $0.02 \%$ by weight) (EU, 2016) and banned in the production of baby bottles in 2011 (EU, 2011; EU, 2013) in the European Union.

The potential toxicity and estrogenic activity of BPA and its gradual removal from some consumer products have led to its replacement by congeners, which have similar physicochemical properties (Barboza et al. 2020). BPA and its most replacements have a similar chemical structure with two p-hydroxyphenyl functional moieties (Siracusa et al. 2018; Usman et al. 2019). Therefore, bisphenol congeners (BPs) may potentially have a similar endocrine-disrupting capacity and may exert similar or even worse adverse effects on the reproductive system (Zhang et al. 2016; Wang et al. 2017a). Several studies show that structural congeners, such as bisphenol AF (BPAF), bisphenol G (BPG), bisphenol M (BPM), bisphenol P (BPP), bisphenol X (BPX), and bisphenol Y (BPY), exert estrogenic activities and displayed toxicological effects at concentrations similar to bisphenol A (Chen et al. 2016; Pelch et al. 2019; Lin et al. 2021; Sauer et al. 2021). For instance, compared to BPA, BPAF was more toxic to Daphnia magna and the obtained No Observed Effect Concentrations (NOEC) (21 days) were 5 and $0.23 \mathrm{mg}$ $\mathrm{L}^{-1}$, respectively (Tisler et al. 2016). The acute toxicity of BPAF, BPP, BPY, and BPX to adult zebrafish was at high toxic level $\left(96 \mathrm{~h}, \mathrm{LC}_{50}: 2.47,0.37 ; 2.63\right.$ and $2.28 \mathrm{mg} \mathrm{L}^{-1}$, respectively), lower than that of $\mathrm{BPA}\left(96 \mathrm{~h}, \mathrm{LC}_{50}: 8.09 \mathrm{mg}\right.$ $\mathrm{L}^{-1}$ ) (Liu et al. 2021). The extensive use of BPs in the production of BPA-free products leads to their widely detection in the aquatic environment at concentration from $\mathrm{ng} \mathrm{L}^{-1}$ to $\mu \mathrm{g} \mathrm{L}^{-1}$ level (Chen et al. 2016; Zhao et al. 2019).

Microalgae, as primary producers that can be found in most aquatic systems, play a pivotal role in preserving their ecological balance (Lemley et al. 2016; Czarny et al. 2017). Pollutants, such as BPA and its structural congeners, may cause changes in the species composition of the phytoplankton community and affect the proper functioning of the entire ecosystem (Ma 2005). Therefore, a lack of research data about possible toxic effects of BPs on microalgae, as an important part of aquatic community, is concerning. To the best of our knowledge, the adverse effects of exposure of microalgae to structural congeners of BPA have not been published so far. In this study, the freshwater microalgae Chlorella vulgaris and Desmodesmus armatus were used to determine the toxic effects of BPA, its six congeners, and their mixture. Moreover, the present investigation aimed to assess environmental risk of individual compound and mixture of bisphenol A and its congeners, which occur together in the environment.

\section{Material and methods}

\section{Chemicals}

Bisphenol A (>97\%) and bisphenol G (>98\%) were purchased from Sigma-Aldrich (USA). Bisphenol AF (>99\%), bisphenol M (>98\%), bisphenol P (>98\%), bisphenol $\mathrm{X}(\mathrm{AP})(>98 \%)$, and bisphenol Y (Z) (98\%) were supplied by TCI (Japan) (Table 1). Stock solutions containing $10 \mathrm{mg} \mathrm{mL}^{-1}$ of BPA and its congeners were prepared daily in methanol (Chemsolve, Poland). All other chemical compounds were of analytical or HPLC grade.

\section{Tested organisms and culture conditions}

Cultures of Chlorella vulgaris (BA-0002) and Desmodesmus armatus (BA-0006) were acquired from the University of Gdansk. Algal species were cultivated in the phytotron chamber (Pol-Eko, Poland) in $250 \mathrm{~mL}$ Erlenmeyer flask on a rotatory shaker $(100 \mathrm{rpm})$ in $100 \mathrm{~mL} \mathrm{BG}-11$ mineral medium (pH 7.64 \pm 0.02 ) (Rippka et al. 1979). Algae were grown in the photoperiod in the day/night cycle $14 / 10 \mathrm{~h}$, temperature $26 / 21{ }^{\circ} \mathrm{C}$ with a constant humidity of $30 \%$ under white light $\left(60 \mu \mathrm{mol}\right.$ photons $\left.\mathrm{m}^{-2} \mathrm{~s}^{-1}\right)$. All experiments were performed using cultures at the logarithmic growth phase. The cell densities at the beginning of the experiment were $7.6 \times 10^{4}$ for $C$. vulgaris and $4.2 \times 10^{4}$ cells $\mathrm{mL}^{-1} D$. armatus.

\section{Toxicity tests}

Chlorella vulgaris and D. armatus were cultured in the presence of the following BPs: BPA, BPAF, BPG, BPM, BPP, BPX, BPY. The cultures were also exposed to a mixture of BPA and its six congeners (MIX). The MIX was prepared by mixing of each pollutants together at equal proportion $(1: 1: 1: 1: 1: 1: 1)$ to obtain the same final concentration as for single substance. The final experimental concentration of examined BPs was chosen based on the results of the rangefinding test. After preliminary assays, tested compounds were added to the $100 \mathrm{~mL}$ cultures of $C$. vulgaris and $D$. armatus (in the range of 5 to $100 \mathrm{mg} \mathrm{L}^{-1}$ ). The control 
Table 1 Physical and chemical properties, and predicted toxic effect of bisphenol A and its structural congeners

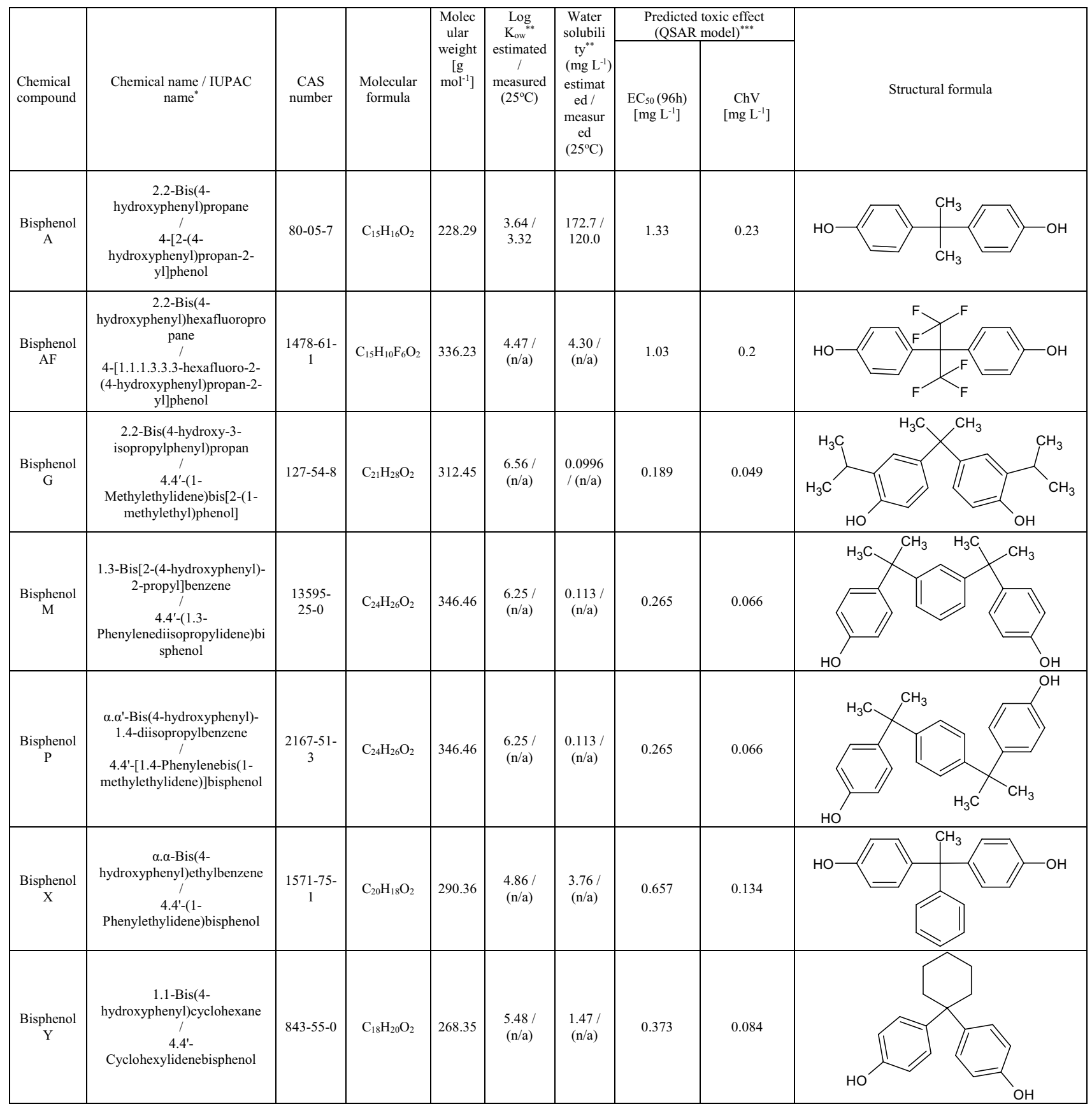

*Calculated by LexiChem 2.6.6. **Calculated by EPI Suite KOWWIN v.1.68 (US EPA). ***Calculated by ECOSAR Class Program v2.0 (US EPA)

samples were cultured on the same medium and in the same conditions, but without the presence of BPs. The concentration of methanol in the tested and control sample was lower than $1 \%$ (v/v) and had no toxicity effects towards both microalgae species. The biomass productivity and chlorophyll $a$ content were determined after 1, 2, 3, 4, 7, 8, 10, 11 , and 14 days of exposure to the tested pollutants and in control samples. $\mathrm{pH}$ and concentration of BPs in medium were monitored at the beginning of the experiment and after 4, 7, 11, and 14 days. Each treatment had five replications.

\section{Measurement of pH, biomass, and chlorophyll $a$ content}

The growth of $C$. vulgaris and D. armatus was assessed by $\mathrm{pH}$, biomass productivity and chlorophyll $a$ content 
determinations. $\mathrm{pH}$ was measured with a $\mathrm{pH}$ meter (Multi 3430 SETF, WTW, Germany). The biomass concentration was assessed by gravimetric method (Czarny et al. 2019a; b). In order to measure the dry weight, 10 -mL algal suspension aliquots were filtered through pre-weighed and precombusted nylon membrane filters. Afterwards, the filters were dried at $105^{\circ} \mathrm{C}$ for $1 \mathrm{~h}$ to a constant weight and then weighed again. The biomass concentration was determined by calculating the difference between the initial and final dry weight of filters. The chlorophyll $a$ content was evaluated by AlgaeChek Ultra fluorometer (Modern Water, UK) (Czarny et al. 2019c). The number of the algal cells at the beginning of experiment was measured using a Fuchs-Rosenthal haemocytometer.

\section{Statistical analyses}

Data were analyzed using Q-Dixon test for detection of outliers (Dixon 1953). All results were expressed as mean values with standard deviation (SD) of five independent replicates. To determine significant differences among the control sample and BPs treatments, the obtained results were statistically assessed by one-way ANOVA using the Statistica v.13.3 software (StatSoft, USA). Values of $P$ lower than 0.05 were considered statistically significant.

Percentage inhibition (PI) was calculated according to the following formula (Eq. 1) (Czarny et al. 2021):

$\% P I=\left(\frac{\mathrm{b}_{c}-\mathrm{b}_{t}}{\mathrm{~b}_{c}}\right) \times 100$

where $b_{c}$, biomass content of control sample; $b_{t}$, biomass content of test sample.

The concentration-response curve, concentration-response equation, and effective concentration at which $50 \%$ inhibition occurs $\left(\mathrm{EC}_{50}\right)$ were calculated by Microsoft Excel (Microsoft, USA) using linear log method based on the biomass content. The combined toxicity of BPA and its six structural congeners was achieved using the Keplinger evaluation system, in which the expected $\mathrm{EC}_{50}$ values were compared with the obtained $\mathrm{EC}_{50}$ values (14 days) and expressed as a ratio (Keplinger and Deichmann 1967).

\section{Results}

In most cases BPs showed a strong inhibition activity against $C$. vulgaris and D. armatus (Fig. 1, Fig. 2 Table S1, Table S2, Table S3, Table S4). Compared to control samples, the biomass and chlorophyll $a$ content of the algae species were increased in a time- and concentration-dependent manner. The percentage inhibition values in response to BPs treatment were calculated for different concentrations and times (1-14 days) of incubation based on the measured biomass content. As shown in Fig. 2, compared with the control samples, BPA, BPAF, BPG, BPX, and MIX have strongly negative effects on $D$. armatus and lead to algal cell death. The maximum percentage inhibition value for BPG and BPX was $100 \%$ at $50 \mathrm{mg} \mathrm{L}^{-1}$ treatments on the 3rd day, while bisphenol $\mathrm{G}$ exerted in lethal effect at $25 \mathrm{mg}$ $\mathrm{L}^{-1}$ on the 11th day of incubation. During the 2nd and 10th day, MIX and BPA exerted lethal effect at concentrations higher than $75 \mathrm{mg} \mathrm{L}^{-1}$, respectively. Similar effect was observed for BPAF at $100 \mathrm{mg} \mathrm{L}^{-1}$ treatments on day 4. For C. vulgaris, $100 \%$ of the cells were killed under BPG and BPX concentrations of $50-100 \mathrm{mg} \mathrm{L}^{-1}$ on the 11th day of exposure, while BPG showed lethal effect also at $75 \mathrm{mg}$ $\mathrm{L}^{-1}$ already within 8th day of treatment. Compared with the control samples, BPM and BPA, BPAF, MIX significantly $(P<0.05)$ inhibited the growth of $D$. armatus and $C$. vulgaris (even to $74.37 \%$ compared to the control sample). The growth of $C$. vulgaris was moderately inhibited by BPM and BPY, for which the maximum percentage inhibition values were $40.38-55.21$ and $55.63-59.64 \%$ at $25-100 \mathrm{mg} \mathrm{L}^{-1}$ after the 14th day of incubation. BPY was moderately toxic to $D$. armatus, for which the growth of cultures was inhibited (29.92-44.94\%) at concentrations higher than $25 \mathrm{mg}$ $\mathrm{L}^{-1}$ on 3rd day of treatment. BPP had a negligible adverse effect on $C$. vulgaris and D. armatus and no lethal or growth stimulating effects were observed. However, in some cases, a hormesis (stimulating) effect on the growth of $C$. vulgaris and $D$. armatus was observed at low concentrations of BPs (5-25 mg L ${ }^{-1}$ ) or on the 1st day of incubation. The maximum stimulating effect was $6.56 \%$ at $25 \mathrm{mg} \mathrm{L}^{-1} \mathrm{BPX}$ treatment ( 1 day) for C. vulgaris and $40.81 \%$ at $25 \mathrm{mg} \mathrm{L}^{-1}$ BPP treatment (14 days) for D. armatus, respectively.

The $\mathrm{pH}$ of $C$. vulgaris and D. armatus cultures exposed to BPs increased in a concentration-dependent manner (Fig. 3 and Fig. 4). pH varied following treatment with BPs at different concentrations (5-100 $\mathrm{mg} \mathrm{L}^{-1}$ ) during the 14-day test periods. The $\mathrm{pH}$ of the algal cultures ranged from the initial value of 7.64 to a final value between 8.14-9.66 and 7.74-9.83, respectively. The $\mathrm{pH}$ values at high concentrations were significantly lower than the control sample, indicating that increasing concentration had an inhibiting effect on photosynthesis.

Table 2 summarizes the calculated $\mathrm{EC}_{50}$ values $(4,7$, and 14 days) for $C$. vulgaris and D. armatus exposed to seven different BPs and their mixture based on the measured biomass content. The toxic effects of BPA and its structural congeners were dependent on both concentration and exposure time. With respect to the determined $\mathrm{EC}_{50}$ values (14 days), a highly toxic effect on $D$. armatus cells was observed for BPA, BPAF, BPG, BPM, and BPX ( $\mathrm{EC}_{50}$ : 42.06, 34.76, $18.84,28.24,26.80 \mathrm{mg} \mathrm{L}^{-1}$, respectively), moderate for BPY $\left(\mathrm{EC}_{50}: 82.65 \mathrm{mg} \mathrm{L}^{-1}\right)$ and the weakest for BPP (no 
Fig. 1 The percentage of inhibition of $C$. vulgaris exposed to individual and combined compounds (a BPA, b BPAF, $\mathbf{c}$ BPG, $\mathbf{d}$ BPM, e BPP, f BPX, $\mathbf{g}$ BPY, and $\mathbf{h}$ MIX) for 14 days. Error bars indicate SD $(n=5)$

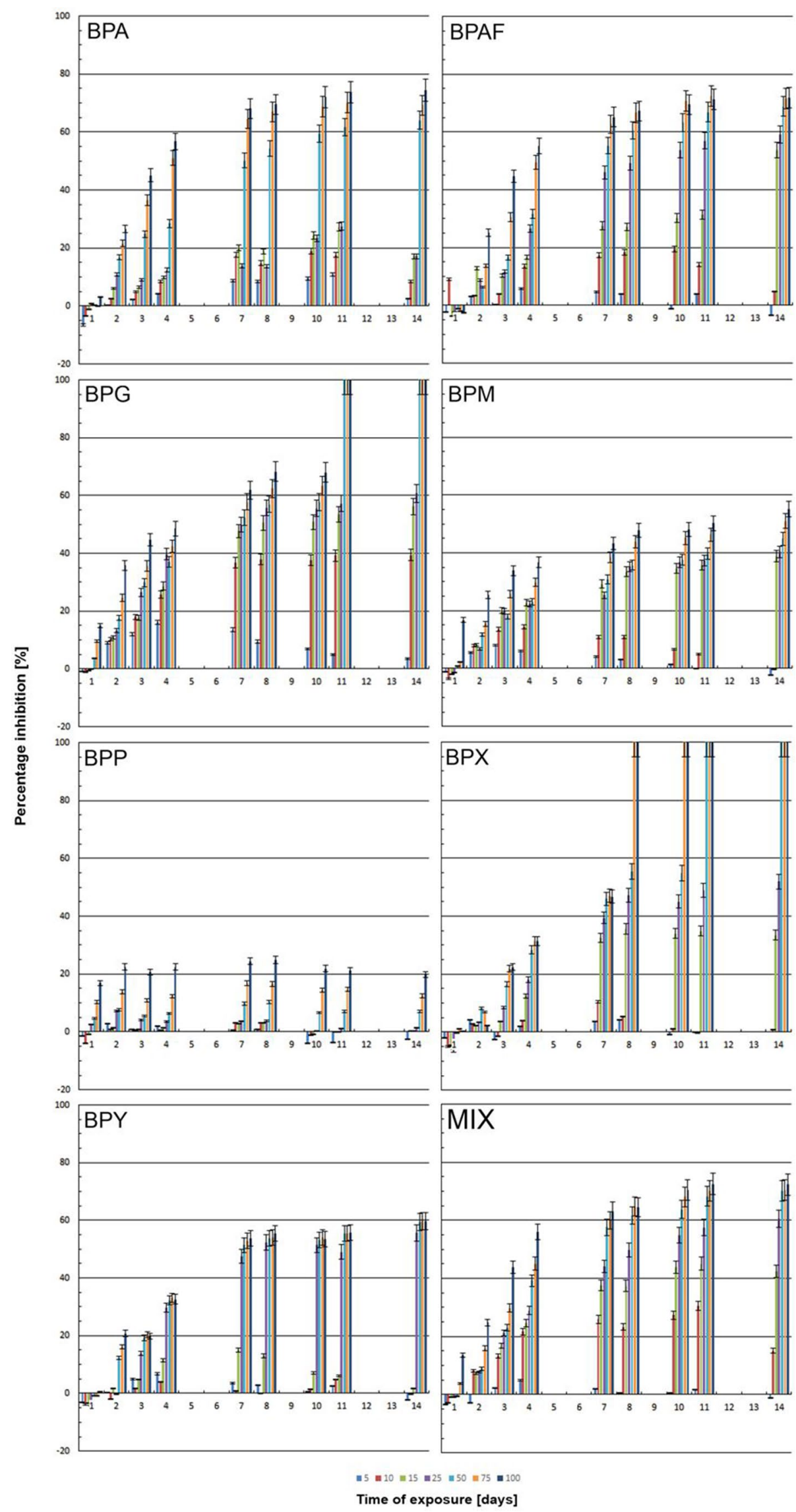


Fig. 2 The percentage of inhibition of D. armatus exposed to individual and combined compounds (a BPA, b BPAF, $\mathbf{c}$ BPG, $\mathbf{d}$ BPM, e BPP, f BPX, $\mathbf{g}$ BPY, and $\mathbf{h}$ MIX) for 14 days. Error bars indicate SD $(n=5)$

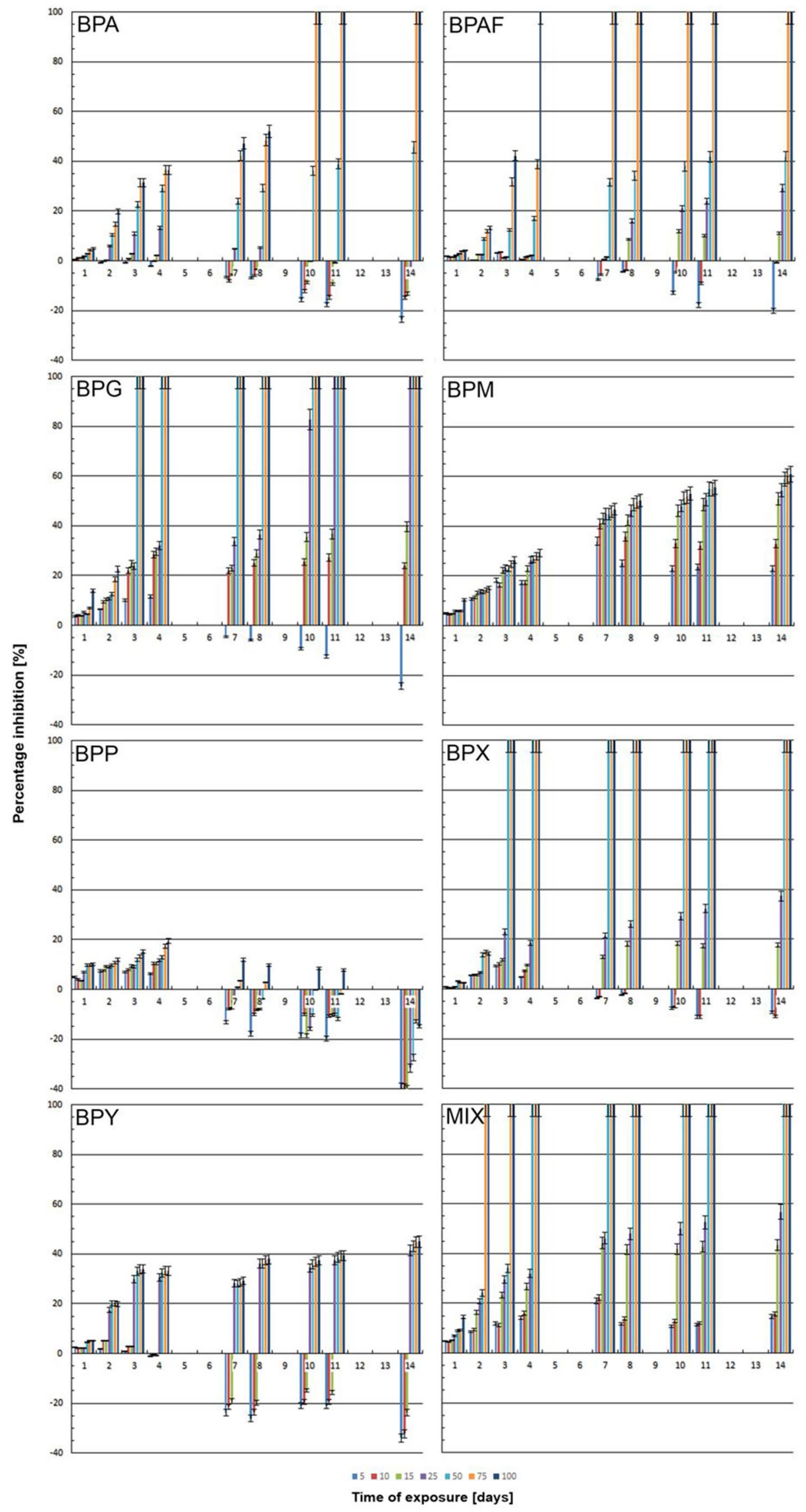


Fig. 3 Effect of individual and combined compounds (a BPA, b BPAF, c BPG, d BPM, e BPP, f BPX, $\mathbf{g}$ BPY, and $\mathbf{h}$ MIX) on $\mathrm{pH}$ of $C$. vulgaris. Error bars indicate $\operatorname{SD}(n=5)$
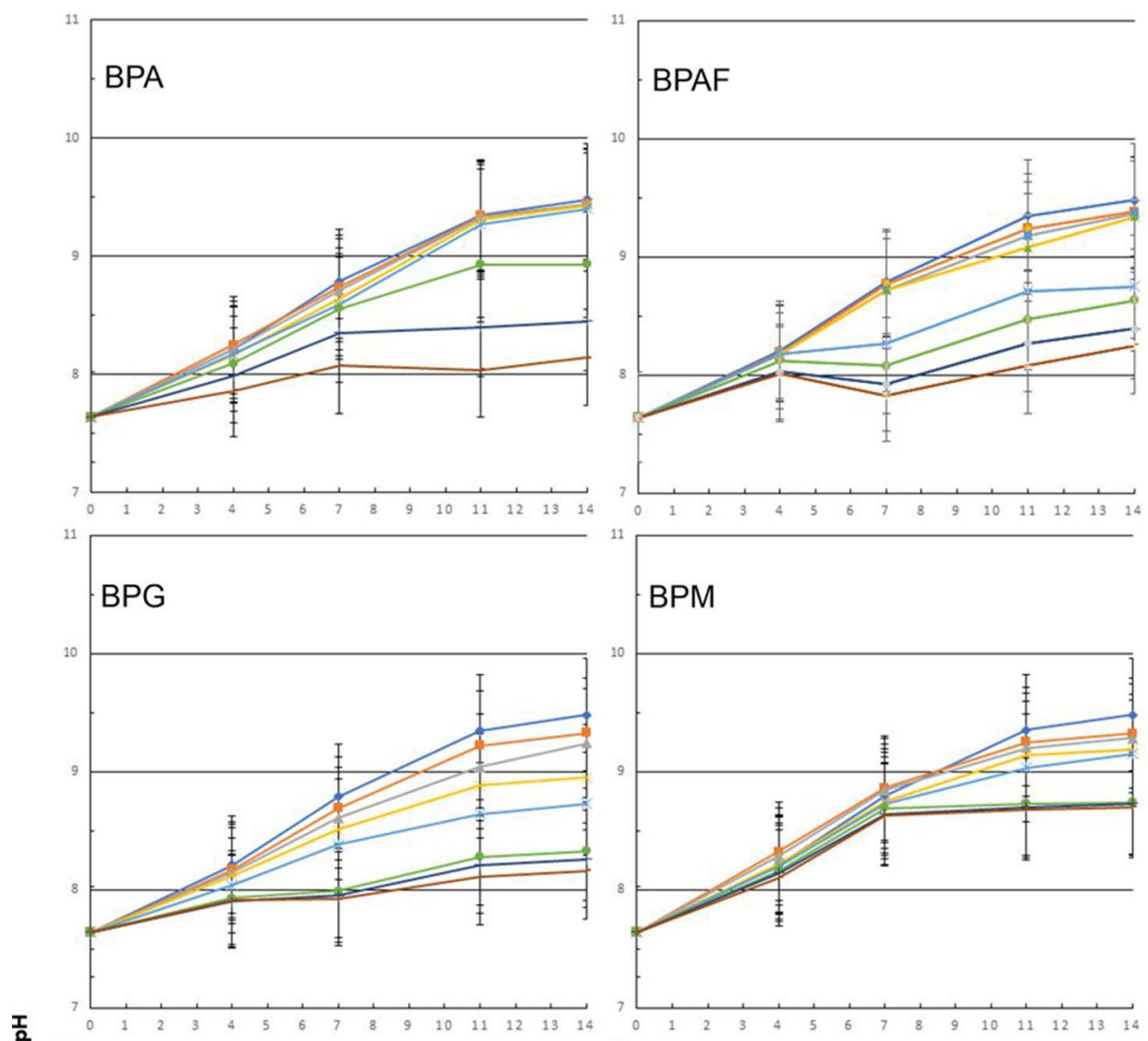

$\frac{1}{2}$
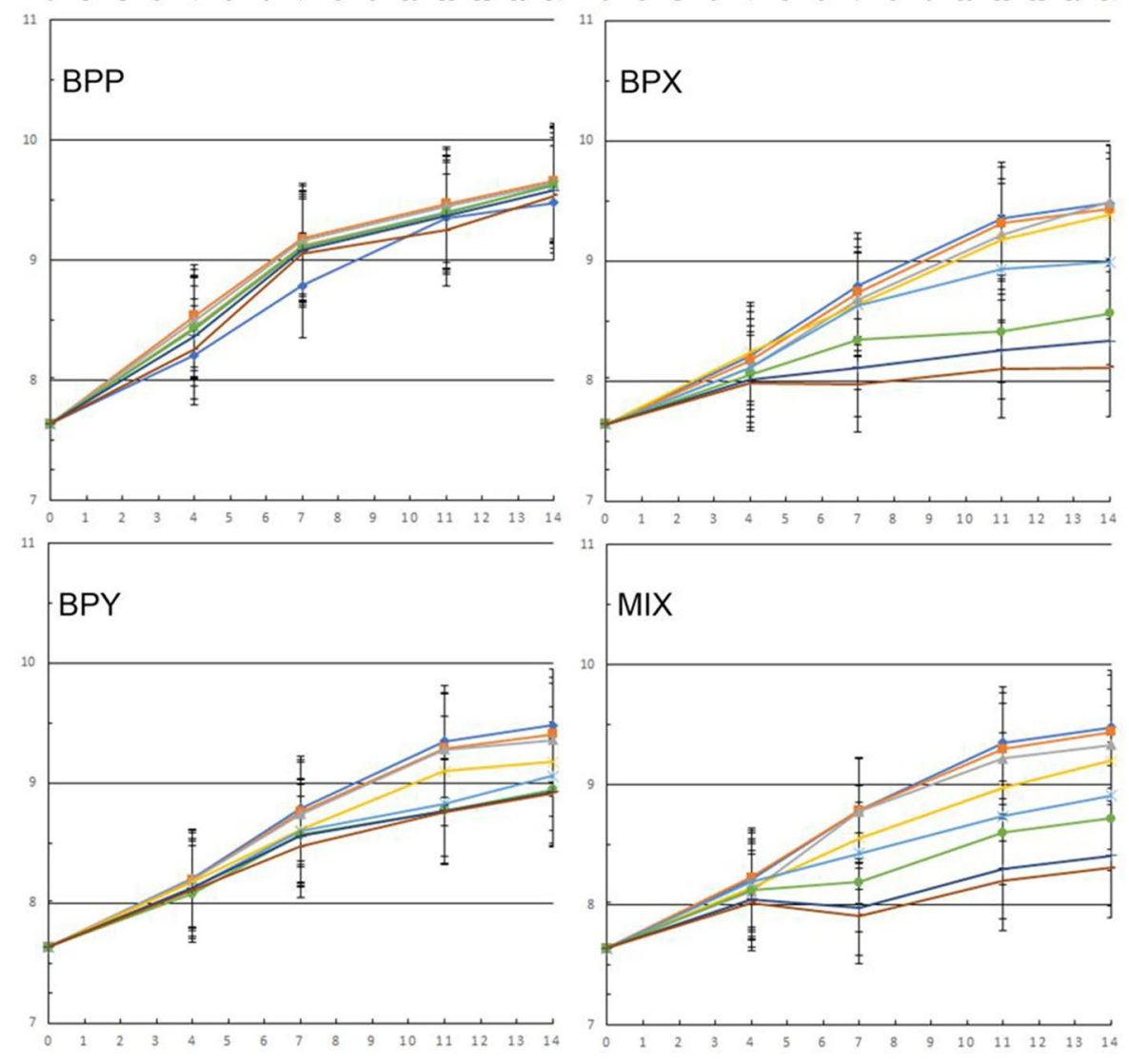

Time of exposure [days] 
Fig. 4 Effect of individual and combined compounds (a BPA, b BPAF, c BPG, d BPM, e BPP, f BPX, $\mathbf{g}$ BPY, and $\mathbf{h}$ MIX) on $\mathrm{pH}$ of $D$. armatus. Error bars indicate $\mathrm{SD}(n=5)$

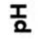
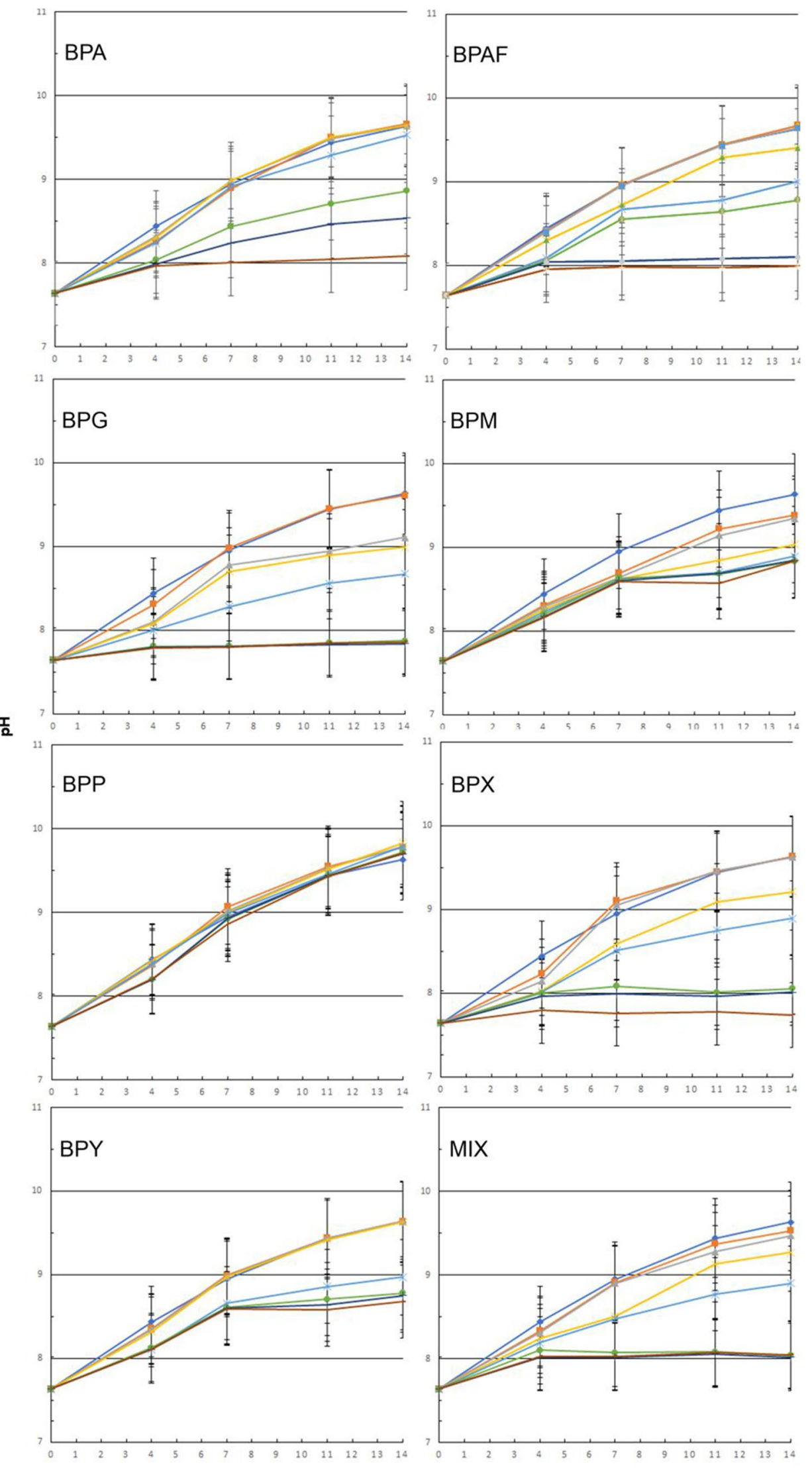

Time of exposure [days] 
Table 2 The effective concentration values $\left(\mathrm{EC}_{50}(14 \mathrm{~d})\right)$ of bisphenol A and its structural congeners for microalgae C.vulgaris and D. armatus

\begin{tabular}{|c|c|c|c|c|}
\hline \multirow[t]{2}{*}{ BPs } & \multicolumn{2}{|l|}{ Chlorella vulgaris } & \multicolumn{2}{|l|}{ Desmodesmus armatus } \\
\hline & Dose response equation $\left(\mathrm{R}^{2}\right)$ & $\begin{array}{l}\mathrm{EC}_{50} \pm \mathrm{SD} \\
{\left[\mathrm{mg} \mathrm{L}^{-1}\right]}\end{array}$ & Dose response equation $\left(\mathrm{R}^{2}\right)$ & $\begin{array}{l}\mathrm{EC}_{50} \pm \mathrm{SD} \\
{\left[\mathrm{mg} \mathrm{L}^{-1}\right]}\end{array}$ \\
\hline BPA & $y=-0.624 x+1.516(0.9016)$ & $42.52 \pm 2.13$ & $y=-1.056 x+2.215(0.8561)$ & $42.06 \pm 2.10$ \\
\hline BPAF & $y=-0.609 x+1.391(0.8225)$ & $28.99 \pm 1.45$ & $y=-0.946 x+1.958(0.9196)$ & $34.76 \pm 1.74$ \\
\hline BPG & $y=-0.751 x+1.399(0.9465)$ & $15.76 \pm 0.79$ & $y=-0.966 x+1.732(0.8451)$ & $18.84 \pm 0.94$ \\
\hline BPM & $y=-0.451 x+1.308(0.8271)$ & $62.12 \pm 3.11$ & $y=-0.287 x+0.917(0.8539)$ & $28.24 \pm 1.41$ \\
\hline BPP & $y=-0.154 x+1.160(0.8420)$ & $19,930.34 \pm 996.52 *$ & $y=-0.226 x+1.615(0.8426)$ & $84,735.72 \pm 4236.77 *$ \\
\hline BPX (BPAP) & $y=-0.922 x+1.745(0.9351)$ & $22.42 \pm 1.12$ & $y=-1.032 x+1.974(0.9211)$ & $26.80 \pm 1.34$ \\
\hline BPY (BPZ) & $\begin{array}{l}y=-0.591 x+1.498 \\
(0.8105)\end{array}$ & $48.76 \pm 2.44$ & $y=-0.744 x+1.927(0.8175)$ & $82.65 \pm 4.13$ \\
\hline MIX & $y=-0.586 x+1.353(0.8996)$ & $28.56 \pm 1.43$ & $y=-0.786 x+1.490(0.9342)$ & $18.22 \pm 0.91$ \\
\hline
\end{tabular}

lethal and growth stimulating effect). The toxicity of BPA, BPAF, BPG, and BPX (EC : $_{0}: 42.52,28.99,15.76,22.42 \mathrm{mg}$ $\mathrm{L}^{-1}$, respectively) suggested that these BPs induced stronger harmful effect to $C$. vulgaris than BPM and BPY $\left(\mathrm{EC}_{50}\right.$ : 62.12 and $48.76 \mathrm{mg} \mathrm{L}^{-1}$, respectively). Toxic effects of mixture to $C$. vulgaris and D. armatus were higher than the sum of individual effect of each mixture component (14 days, $\mathrm{EC}_{50}$ : 28.56 and $18.22 \mathrm{mg} \mathrm{L}^{-1}$, respectively). Generally, it can be concluded that $D$. armatus was more sensitive to tested BPs than $C$. vulgaris (mean $\mathrm{EC}_{50}$ value of all tested BPs, 14 days: 38.89 and $46.52 \mathrm{mg} \mathrm{L}^{-1}$, respectively). With respect to $\mathrm{EC}_{50}$ values $(14 \mathrm{~d})$, BPs toxicity decreases in the order: $\mathrm{BPG}>\mathrm{BPX}>\mathrm{MIX}>\mathrm{BPAF}>\mathrm{BPA}>\mathrm{BPY}>\mathrm{BPM}>$ BPP for C. vulgaris and $\mathrm{MIX}>\mathrm{BPG}>\mathrm{BPX}>\mathrm{BPM}>\mathrm{BPA}$ $\mathrm{F}>\mathrm{BPA}>\mathrm{BPY}>\mathrm{BPP}$ for D. armatus.

\section{Discussion}

For some decades BPs have been intensively introduced into the terrestrial and aquatic ecosystems without previous research about their potential harmful impact on organisms (Michałowicz 2014; Tisler et al. 2016). In this study, the adverse effects of BPAF, BPG, BPM, BPP, BPX, and BPY to $C$. vulgaris and D. armatus were investigated for the first time and the results were compared to the toxicity of bisphenol A. Several studies have shown that BPA was toxic to green algae (Staples et al. 1998; Liu et al. 2010; Seoane et al. 2021). In the present study, the $\mathrm{EC}_{50}$ values (14 days) for $C$. vulgaris and D. armatus were 42.52 and $42.06 \mathrm{mg} \mathrm{L}^{-1}$, respectively. Similar findings were reported by Ji et al. (2014) that the $\mathrm{EC}_{50}(120 \mathrm{~h})$ of bisphenol A for C. vulgaris was $39.80 \mathrm{mg} \mathrm{L}^{-1}$. Esperanza et al. (2020) also found that bisphenol A was harmful to Chlamydomonas reinhardtii with $\mathrm{EC}_{50}$ of $32.40 \mathrm{mg} \mathrm{L}^{-1}$ (3 days). The $\mathrm{EC}_{50}$ values (3 days) for Stephanodiscus hantzschii was $8.65 \mathrm{mg}$ $\mathrm{L}^{-1}$ (Li et al. 2009), which are similar to that found for Scenedesmus quadricauda $\left(13.23 \mathrm{mg} \mathrm{L}^{-1}\right)$ by (Xiang et al. 2018). The results achieved in the present study showed that in most cases, BPAF, BPG, BPM, and BPX (14 days, $\mathrm{EC}_{50}$ : 15.76-34.76 $\mathrm{mg} \mathrm{L}^{-1}$ ) had higher toxicities to $C$. vulgaris and D. armatus in comparison to BPA (14 days, $\mathrm{EC}_{50}: 42.52$ and $42.06 \mathrm{mg} \mathrm{L}^{-1}$, respectively). Therefore, the industrial replacement of BPA with congeners, such as BPAF, BPG, $\mathrm{BPM}$, and BPX, is questionable. Unfortunately, there are only few available data about toxic effects of structural congeners of BPA to microalgae. For instance, Tisler et al. (2016) reported that BPAF (3 days, $\mathrm{IC}_{50}: 3.00 \mathrm{mg} \mathrm{L}^{-1}$ ) was more harmful to Desmodesmus subspicatus than BPA (3 days, $\mathrm{IC}_{50}$ : $19.60 \mathrm{mg} \mathrm{L}^{-1}$ ). Ding et al. (2020) found that bisphenol $\mathrm{S}$ showed stronger toxicity to $C$. vulgaris than bisphenol $\mathrm{A}$, and the obtained $\mathrm{EC}_{50}$ values $(2 \mathrm{~d})$ were 3.16 and $41.43 \mathrm{mg} \mathrm{L}^{-1}$, respectively. Unfortunately, no data are available for adverse effects of BPG, BPM, BPP, BPX, and BPY to microalgae.

BPs have been widely used in industry as alternatives of BPA, which have been widely detected in different environmental and biological samples (Wang et al. 2020; Liu et al. 2021). As a result, variety of this substitutes coexisting in aquatic environment; thus, the microalgae are exposed to these chemicals simultaneously. In aquatic ecosystems, the combined effect of chemical compounds may be stronger (e.g. synergistic) or weaker (e.g. antagonistic) as they would be predicted on the basis of response addition (Gebara et al. 2020). Thus, the investigation of adverse impact of bisphenol $\mathrm{A}$ and its structural congeners in complex mixtures is highly important to assess their environmental risk in a more realistic way. Hence, this study was designed to investigated the toxic effect of mixture of seven BPs (BPA, BPAF, BPG, $\mathrm{BPM}, \mathrm{BPP}, \mathrm{BPX}$, and BPY) on the microalgae $C$. vulgaris 
and $D$. armatus for the first time. Keplinger and Deichmann (1967) showed that the ratio of expected to observed $\mathrm{EC}_{50}$ values of 1.75 and higher indicated a synergistic effect. The results showed that the expected $\mathrm{EC}_{50}$ values of mixture were 2878.70 and $12138.44 \mathrm{mg} \mathrm{L}^{-1}$ and the $\mathrm{EC}_{50}$ values were 28.56 and $18.22 \mathrm{mg} \mathrm{L}^{-1}$ for $C$. vulgaris and $D$. armatus, respectively. Thus, the mixture of BPA and its six structural congeners exhibited synergistic effects, because the ratio was higher than 1.75. Synergic toxicity for BPs is of high concern, because the predictable harmful effect for the green algae based on the individual chemicals would underestimate the mixture impact. Moreover, the results of our study indicated that mixture of bisphenol A and its six structural congeners were more harmful to the tested microalgae than BPA (average 14 day, $\mathrm{EC}_{50}: 42.29 \mathrm{mg} \mathrm{L}^{-1}$ ). Elersek et al. (2021) assessed the toxicity of the binary mixture of BPA and BPF in the green algae Pseudokirchneriella subcapitata, and the results showed an additive effect at a lower concentration and antagonism at a higher concentration. Unfortunately this study is the only published report on the toxicity of mixture of bisphenol A and its six congeners in microalgae.

The investigations on toxic effects of BPs on algae are not available. Therefore, the mechanisms of their action are not well understood yet and may be related to several factors occurring simultaneously. The molecular structure and physicochemical properties of BPs may affect environmental behavior and fate of BPs. In this work, the US Environmental Protection Agency (US EPA) EPI Suite KOWWIN version 1.68 was used to estimate physicochemical properties such as octanol-water partition coefficient $\left(\log _{\text {Kow }}\right)$ and water solubility. The calculated $\log _{\text {Kow }}$ values of BPs were 3.64-6.56 (Table 1). Thus, due to their hydrophobic character $\left(\log _{\text {Kow }}>3\right)$, they can easily cross the cell wall of microalgae and bioaccumulate. Moreover, ECOSAR Class Program v2.0, which employs quantitative structure-activity relationship (QSAR) models, was used to estimate the toxic effect of BPs (Czarny et al. 2021). The calculated toxicity (the $\mathrm{EC}_{50}$, chronic value $(\mathrm{ChV})$ for algae) (Table 1 ) indicates that BPA shows relatively lower toxic effect than the other tested BPs. The experimental data obtained in this study show that BPY, BPM, BPP (C. vulgaris) and BPY, BPP (D. armatus) demonstrated lower toxicity than BPA. The obtained results showed that BPs at low concentrations may lead to stimulation of the growth of $C$. vulgaris and $D$. armatus but exhibited inhibitory effect at higher concentrations. Therefore, the response of tested microalgae exposed to increasing dose of BPs can be regarded as hormetic. Similar findings were reported by Zhu et al. (2021), and they found that trans-4-hydroxy-3-methoxycinnamic acid promoted the growth of freshwater microalgae Euglena gracilis at low concentrations $\left(0.5 \mathrm{~g} \mathrm{~L}^{-1}\right)$ and show toxic effect at high concentration $\left(>1 \mathrm{~g} \mathrm{~L}^{-1}\right)$. Hormesis is defined in toxicological sciences as a biphasic dose-response phenomenon characterized by low concentration promotion and high concentration inhibitory effect, which may be characterized by a U- or inverted U-shaped dose-response curve (Calabrese 2008; Mattson 2008; Nweke and Ogbonna 2017, He et al. 2020). Several studies have shown that this phenomenon is related to the activation of adaptive responses required to protect cells from pollutants (Zhang 2008; Zhang et al. 2009). In turn, de Morais et al. (2014) reported that low dose of toxic substance might promote cell division. Therefore, in this study, stimulation of the growth of $C$. vulgaris and $D$. armatus may be an attempt to provide a dilution effect of BPs as its dose will be divided for a larger amount of biomass. The occurrence of growth promotion effect phenomenon may have unexpected implications for ecological risk assessment. Therefore, due to phenomenon of hormesis, actual measurements from laboratory studies are more reliable for environmental risk assessments of aquatic contaminants than estimated by QSAR model. The accurate quantification of chlorophyll $a$ content is a parameter which is used to examine the adverse effect of environmental pollutants on algae (Kasahara et al. 2002; Ding et al. 2020). In this study, with respect to the control sample, chlorophyll $a$ content decreased in a concentration dependent manner of BPs for both algae species. A reduction in chlorophyll $a$ content might be caused to the stress response in algae that can be owing by the degradation of PSII complex or the peroxidation of thylakoids lipid (Xiong et al. 2016). These results were in agreement with the observations reported by $\mathrm{Li}$ et al. (2009), who showed significant reductions in the chlorophyll $a$ content of $S$. hantzschii exposed to BPA at concentrations higher than $1 \mathrm{mg} \mathrm{L}^{-1}$. In addition, they showed that at a concentration higher than $5 \mathrm{mg} \mathrm{L}^{-1}$, cell division was inhibited and the degradation of chloroplasts and chlorophyll occurred. During photosynthesis green algae consume dissolved carbon dioxide which is responsible for an increase in $\mathrm{pH}$ (Gerardi and Lytle 2015). The $\mathrm{pH}$ values of the $C$. vulgaris and $D$. armatus cultures with higher concentration of BPs $\left(>25 \mathrm{mg} \mathrm{L}^{-1}\right)$ were almost the same as the initial value due to low growth (7.74-9.00). Therefore, lower $\mathrm{pH}$ levels compared to the control sample might have appeared due to the photosynthesis inhibition. A similar trend was noticed by Ji et al. (2014), who found that after 10 days of exposure to $50 \mathrm{mg} \mathrm{L}^{-1}$ of bisphenol $\mathrm{A}$, the $\mathrm{pH}$ of the $C$. vulgaris culture was almost the same as the initial level (6.6). Wang et al. (2017b) found that $\mathrm{pH}$ levels of Desmodesmus sp.WR1 cultures exposed to BPA were lower with respect to the control sample at concentrations higher than $3 \mathrm{mg} \mathrm{L}^{-1}$ BPA.

Zhang et al. (2014) noticed that Chlorella pyrenoidosa has lower sensitivity to BPA than Scenedesmus obliquus with $\mathrm{EC}_{50}$ (4 days) of 63.53 and $26.72 \mathrm{mg} \mathrm{L}^{-1}$, respectively. Similar findings have been reported for $C$. pyrenoidosa 
(3 days $\mathrm{EC}_{50}: 44.90 \mathrm{mg} \mathrm{L}^{-1}$ ) and S. obliquus (3 days $\mathrm{EC}_{50}$ : $33.90 \mathrm{mg} \mathrm{L}^{-1}$ ) by Li et al. (2017), which is in agreement with the presented research. Cell walls play an important role in the migration of pollutants inside the microorganisms. Therefore, the differences in the sensitivities towards BPs between tested microalgae might be due to the different cellular structure and cell wall composition. Chlorella vulgaris is a spherical, unicellular microalgae and its cell wall is mainly constituted of rhamnose and cellulose, which accounts for its rigidity (Safi et al. 2014). Desmodesmus armatus is characterized by coenobia formation of four and eight cells and its cell wall is composed mainly of mannose (Takeda 1995; Dunker and Wilhelm 2018). Moreover, differences in toxicity between species may be related to the bioaccumulation and biodegradability of microalgae. According to previous studies, the degradation pathways vary between green algae species, which leads to production of less or more harmful metabolic products. Therefore, it is possible that $C$. vulgaris degrade BPs to less harmful transformation products and thus was less sensitive than $D$. armatus.

In pursuance of the Council Regulation (EC) No 440/2008, all the tested BPs (14 days $\mathrm{EC}_{50}: 15.76-82.65 \mathrm{mg}$ $\mathrm{L}^{-1}$ ), except BPP (growth stimulating effect), can be classified as harmful to $C$. vulgaris and D. armatus. However, bisphenol $\mathrm{A}$ and its structural congeners are present in aquatic environments at low concentration (ng L $\mathrm{L}^{-1}$ to $\mu \mathrm{g} \mathrm{L}^{-1}$ ). Therefore, the risk posed to microalgae by this pollutant can be classified as negligible. Nevertheless, BPA is one of the most mass-manufactured chemicals worldwide and has over 16 BPs, which have been used as a BPA replacement in the producing of wide-ranging applications. Therefore, their concentrations in aquatic ecosystems are very likely underestimated (Yamazaki et al. 2015; Lalwani et al. 2020).

\section{Conclusions}

The present study demonstrated that BPA and its six structural congeners show an adverse impact on the microalgae C. vulgaris and $D$. armatus. The toxic effects of BPs to both species were concentration and time-dependent. BPs used as a replacement of BPA should not exhibit any toxic effects. Unfortunately, the results obtained in this research show that currently used substitutes, such as BPAF, BPG, BPX (14 days, $\mathrm{EC}_{50}$ : 15.76-28.99 $\mathrm{mg} \mathrm{L}^{-1}$, C. vulgaris) and BPAF, BPG, BPM, BPX (14 days, $\mathrm{EC}_{50}: 18.84-34.76 \mathrm{mg}$ $\mathrm{L}^{-1}$, D. armatus), exert more adverse impact to examined microalgae in comparison to bisphenol A (14 days, $\mathrm{EC}_{50}$ : 42.06-42.52 $\mathrm{mg} \mathrm{L}^{-1}$ ). Therefore, BPs, which are used to replace BPA in the manufacture of 'BPA-free' plastic products, should be implemented with caution to avoid replacing this emerging pollutant with others with similar estrogenic activity or toxic effects. It is noteworthy that also mixture of bisphenols (14 days, $\mathrm{EC}_{50}$ : $18.22-28.56 \mathrm{mg} \mathrm{L}^{-1}$ ) showed stronger toxic effects compared to BPA. The results indicated that mixture of BPA and its six congeners show synergistic effect. Primary producers, such as green algae in aquatic environments are usually exposed to a complex mixture of BPs. Thus, the increased toxicity of combined contaminants may lead to inhibition of their growth and consequently to changes in the species composition of the phytoplankton community, creating a serious threat to proper functioning of the entire ecosystems. Moreover, D. armatus (average 14 days, $\mathrm{EC}_{50}: 38,89 \mathrm{mg} \mathrm{L}^{-1}$ ) was more sensitive than $C$. vulgaris (14 days, mean $\mathrm{EC}_{50}: 46,52 \mathrm{mg} \mathrm{L}^{-1}$ ) to the adverse effect of bisphenol $\mathrm{A}$ and its structural congeners. Based on $\mathrm{EC}_{50}$ values (14 days), the order of the toxicity of $\mathrm{BPs}$ was $\mathrm{BPG}>\mathrm{BPX}>\mathrm{MIX}>\mathrm{BPAF}>\mathrm{BPA}>\mathrm{BPY}>\mathrm{B}$ $\mathrm{PM}>\mathrm{BPP}$ for $C$. vulgaris and $\mathrm{MIX}>\mathrm{BPG}>\mathrm{BPX}>\mathrm{BPM}$ $>$ BPAF $>$ BPA $>$ BPY $>$ BPP for D. armatus. Although a large number of studies have proved the adverse impact of bisphenol A on green algae, studies about potential risk of BPs on these aquatic microorganisms are still lacking. Thus, the occurrence of variety of BPs in aquatic ecosystems, their interactions in a mixture and potential adverse effect merit further investigation.

Supplementary Information The online version contains supplementary material available at https://doi.org/10.1007/s10811-022-02704-3.

Funding This project was financially supported by the National Science Center (NCN) in Krakow, Poland (Grant no. 2020/04/X/ NZ8/01436).

Data availability All data generated or analyzed during this study are included in this published article (and its supplementary information files).

Open Access This article is licensed under a Creative Commons Attribution 4.0 International License, which permits use, sharing, adaptation, distribution and reproduction in any medium or format, as long as you give appropriate credit to the original author(s) and the source, provide a link to the Creative Commons licence, and indicate if changes were made. The images or other third party material in this article are included in the article's Creative Commons licence, unless indicated otherwise in a credit line to the material. If material is not included in the article's Creative Commons licence and your intended use is not permitted by statutory regulation or exceeds the permitted use, you will need to obtain permission directly from the copyright holder. To view a copy of this licence, visit http://creativecommons.org/licenses/by/4.0/.

\section{References}

Barboza LGA, Cunha SC, Monteiro C, Fernandes JO, Guilhermino L (2020) Bisphenol A and its analogs in muscle and liver of fish from the North East Atlantic Ocean in relation to microplastic contamination. Exposure and risk to human consumers. J Hazard Mater 393:122419 
Bhatnagar A, Anastopoulos I (2017) Adsorptive removal of bisphenol A (BPA) from aqueous solution: a review. Chemosphere 168:885-902

Biemann R, Bluher M, Isermann B (2021) Exposure to endocrinedisrupting compounds such as phthalates and bisphenol $\mathrm{A}$ is associated with an increased risk for obesity. Best Pract Res Clin Endocrinol Metab 35:101546

Bjornsdotter MK, de Boer J, Ballesteros-Gomez A (2017) Bisphenol $\mathrm{A}$ and replacements in thermal paper: a review. Chemosphere 182:691-706

Bousoumah R, Leso V, Iavicoli I, Huuskonen P, Viegas S, Porras S, Santonen T, Frery N, Robert A, Nadaw S (2021) Biomonitoring of occupational exposure to bisphenol A, bisphenol $\mathrm{S}$ and bisphenol F: a systematic review. Sci Total Environ 783:146905

Calabrese EJ (2008) Hormesis: why it is important to toxicology and toxicologist. Environ Toxicol Chem 7:1451-1474

Catenza CJ, Farooq A, Shubear NS, Donkor KK (2021) A targeted review on fate, occurrence, risk and health implications of bisphenol analogues. Chemosphere 268:129273

Chen D, Kannan K, Tan H, Zheng Z, Feng YL, Wu Y, Widelka M (2016) Bisphenol analogues other than BPA: environmental occurrence, human exposure, and toxicity-a review. Environ Sci Technol 50:5438-5453

Czarny K, Szczukocki D, Krawczyk B, Gadzała-Kopciuch R, Skrzypek S (2019a) Toxicity of single steroid hormones and their mixtures toward the cyanobacterium Microcystis aeruginosa. J Appl Phycol 31:3537-3544

Czarny K, Szczukocki D, Krawczyk B, Miękoś E, Skrzypek S, Gadzala-Kopciuch R (2019b) Inhibition of growth of Anabaena variabilis population by single and mixed steroid hormones. $\mathrm{J}$ Appl Phycol 31:389-398

Czarny K, Szczukocki D, Krawczyk B, Skrzypek S, Zielinski M, Gadzala-Kopciuch R (2019c) Toxic effects of single animal hormones and their mixtures on the growth of Chlorella vulgaris and Scenedesmus armatus. Chemosphere 224:93-102

Czarny K, Krawczyk B, Szczukocki D (2021) Toxic effects of bisphenol A and its analogues on cyanobacteria Anabaena variabilis and Microcystis aeruginosa. Chemosphere 263:128299

Czarny K, Szczukocki D, Krawczyk B, Zielinski M, Miękoś E, Gadzala-Kopciuch R (2017) The impact of estrogens on aquatic organisms and methods for their determination. Crit Rev Environ Sci Technol 47:909-963

de Morais P, Stoichev T, Basto MCP, Ramos V, Vasconcelos VM, Vasconcelos MTSD (2014) Cyanobacterium Microcystis aeruginosa response to pentachlorophenol and comparison with that of the microalga Chlorella vulgaris. Water Res 52:63-72

Ding T, Li W, Yang M, Yang B, Li J (2020) Toxicity and biotransformation of bisphenol $\mathrm{S}$ in freshwater green alga Chlorella vulgaris. Sci Total Environ 747:141144

Dixon W (1953) Processing data for outliers. Biometrics 9:74-89

Drewes JE, Hemming J, Ladenburger SJ, Schauer J, Sonzogni W (2005) An assessment of endocrine disrupting activity changes during wastewater treatment through the use of bioassays and chemical measurements. Water Environ Res 77:12-23

Dunker S, Wilhelm C (2018) Cell wall structure of coccoid green algae as an important trade-off between biotic interference mechanisms and multidimensional cell growth. Front Microbiol 9:719

ECHA (2017) Member State Committee Unanimously Agrees that Bisphenol A is an Endocrine Disruptor. URL https://echa.europa. eu/documents/10162/769b2777-19cd-9fff-33c4-54fe6d8290d5. Accessed 20 Apr 2021

Elersek T, Notersberg T, Kovacic A, Heath E, Filipic M (2021) The effects of bisphenol A, F and their mixture on algal and cyanobacterial growth: from additivity to antagonism. Environ Sci Pollut Res Int 28:3445-3454
Esperanza M, Seoane M, Servia MJ, Cid A (2020) Effects of Bisphenol A on the microalga Chlamydomonas reinhardtii and the clam Corbicula fluminea. Ecotoxicol Environ Saf 197:110609

EU (2011) Commission implementing regulation 321/2011 of 1 april 2011 amending regulation (EU) No 10/2011 as regards the restriction of use of bisphenol A in plastic infant feeding bottles. Off $\mathrm{J}$ Eur Union L87(2011):1-2

EU (2013) Regulation (EU) 609/2013 of the European parliament and of the council of 12 june 2013 on food intended for infants and young children, food for special medical purposes, and total diet replacement for weight control and repealing council directive 92/52/EEC, commission directives 96/8/EC, 1999/21/EC, 2006/125/EC and 2006/141/EC, directive 2009/39/EC of the European parliament and of the council and commission regulations (EC) No 41/2009 and (EC) No 953/2009. Off J Eur Union L181(2013):35-56

EU (2016) Commission regulation 2016/2235 of 12 december 2016 amending annex XVII to regulation (EC) No 1907/2006 of the European parliament and of the council concerning the registration, evaluation, authorisation and restriction of chemicals (REACH) as regards bisphenol A. Off J Eur Union L337(2016):3-5

Faheem M, Bhandari RK (2021) Detrimental effects of bisphenol compounds on physiology and reproduction in fish: a literature review. Environ Toxicol Pharmacol 81:103497

Frankowski R, Zgola-Grzeskowiak A, Grzeskowiak T, Sojka K (2020) The presence of bisphenol A in the thermal paper in the face of changing European regulations - a comparative global research. Environ Pollut 265:114879

Fu P, Kawamura K (2010) Ubiquity of bisphenol A in the atmosphere. Environ Pollut 158:3138-3143

Fukazawa H, Hoshino K, Shiozawa T, Matsushita H, Terao Y (2001) Identification and quantification of chlorinated bisphenol $\mathrm{A}$ in wastewater from wastepaper recycling plants. Chemosphere 44:973-979

Gebara RC, Alho LOG, Rocha GS, Mansano ADS, Melao M (2020) Zinc and aluminum mixtures have synergic effects to the algae Raphidocelis subcapitata at environmental concentrations. Chemosphere 242:125231

Gerardi M, Lytle B (2015) Algae, Alkalinity, and pH. In: The biology and troubleshooting of facultative lagoons. John Wiley, Hoboken pp 105-110

He N, Liu Z, Sun X, Wang S, Liu W, Sun D, Duan S (2020) Phytotoxicity, bioaccumulation, and degradation of Nonylphenol in different microalgal species without bacterial influences. Int J Molec Sci 21(4): 1338

Huang YQ, Wong CK, Zheng JS, Bouwman H, Barra R, Wahlstrom B, Neretin L, Wong MH (2012) Bisphenol A (BPA) in China: a review of sources, environmental levels, and potential human health impacts. Environ Int 42:91-99

Ji M-K, Kabra A, Choi J, Hwang J-H, Kim J, Abou-Shanab R, Oh Y-K, Jeon B-H (2014) Biodegradation of bisphenol A by the freshwater microalgae Chlamydomonas mexicana and Chlorella vulgaris. Ecol Eng 73:260-269

Kasahara M, Kagawa T, Oikawa K, Suetsugu N, Miyao M, Wada M (2002) Chloroplast avoidance movement reduces photodamage in plants. Nature 420:829-832

Keplinger ML, Deichmann WB (1967) Acute toxicity of combination of pesticides. Toxicol Appl Pharmacol 10:586-595

Lalwani D, Ruan Y, Taniyasu S, Yamazaki E, Kumar NJI, Lam PKS, Wang X, Yamashita N (2020) Nationwide distribution and potential risk of bisphenol analogues in Indian waters. Ecotoxicol Environ Saf 200:110718

Lee H, Part T (2000) Bisphenol-A contamination in Canadian municipal and industrial wastewater and sludge samples. Water Qual Res J Can 35:283-298 
Lemley D, Adams J, Bate G (2016) A review of microalgae as indicators in South African estuaries. South Afr J Bot 107:12-20

Li D, Bi R, Chen H, Mu L, Zhang L, Chen Q, Xie H, Luo Y, Xie L (2017) The acute toxicity of bisphenol A and lignin-derived bisphenol in algae, daphnids, and Japanese medaka. Environ Sci Pollut Res Int 24:23872-23879

Li J, Bach A, Crawford RB, Phadnis-Moghe AS, Chen W, D'Ingillo S, Kovalova N, Suarez-Martinez JE, Zhou J, Kaplan BLF, Kaminski NE (2018) CLARITY-BPA: Effects of chronic Bisphenol A exposure on the immune system: Part 1 - Quantification of the relative number and proportion of leukocyte populations in the spleen and thymus. Toxicology 396-397:46-53

Li R, Chen GZ, Tam NF, Luan TG, Shin PK, Cheung SG, Liu Y (2009) Toxicity of bisphenol A and its bioaccumulation and removal by a marine microalga Stephanodiscus hantzschii. Ecotoxicol Environ Saf 72:321-328

Liang X, Yang R, Yin N, Faiola F (2021) Evaluation of the effects of low nanomolar bisphenol A-like compounds' levels on early human embryonic development and lipid metabolism with human embryonic stem cell in vitro differentiation models. J Hazard Mater 407:124387

Lin J, Deng L, Sun M, Wang Y, Lee S, Choi K, Liu X (2021) An in vitro investigation of endocrine disrupting potentials of ten bisphenol analogues. Steroids 169:108826

Lin Y, Zeng X, Wu D, Wang X, Qu W (2006) Study on bisphenol A induced primary cultured mesencephalic neuronal cell injury by oxidative stress. J Hygiene Res 35:415-423

Liu J, Zhang L, Lu G, Jiang R, Yan Z, Li Y (2021) Occurrence, toxicity and ecological risk of Bisphenol A analogues in aquatic environment - a review. Ecotoxicol Environ Saf 208:111481

Liu Y, Guan Y, Gao Q, Tam NF, Zhu W (2010) Cellular responses, biodegradation and bioaccumulation of endocrine disrupting chemicals in marine diatom Navicula incerta. Chemosphere 80:592-599

Ma J (2005) Differential sensitivity of three cyanobacterial and five green algal species to organotins and pyrethroids pesticides. Sci Total Environ 341:109-117

Makowska K, Lech P, Majewski M, Rychlik A, Gonkowski S (2021) Bisphenol A affects vipergic nervous structures in the porcine urinary bladder trigone. Sci Rep 11:12147

Mattson MP (2008) Hormesis defined. Age Res Rev 7:1-7

Michałowicz J (2014) Bisphenol A - Sources, toxicity and biotransformation. Environ Toxicol Pharmacol 37:738-758

Mustieles V, D'Cruz S, Couderq S, Rodrigez-Carrillo A, Fini J-B, Hofer T, Steffensen I-L, Dirven H, Barouki R, Olea N, Fernandez M, David A (2021) Bisphenol A and its analogues: a comprehensive review to identify and prioritize effect biomarkers for human biomonitoring. Environ Int 144:105811

Nweke CO, Ogbonna CJ (2017) Statistical models for biphasic doseresponse relationships (hormesis) in toxicological studies. Ecotoxicol Environ Contam 12:39-55

Ohore O, Zhang S (2021) Endocrine disrupting effects of bisphenol A exposure and recent advances on its removal by water treatment systems. A review. Scient Afr 5:e00135

Pelch K, Wignall JA, Goldstone AE, Ross PK, Blain RB, Shapiro AJ, Holmgren SD, Hsieh JH, Svoboda D, Auerbach SS, Parham FM, Masten SA, Walker V, Rooney A, Thayer KA (2019) A scoping review of the health and toxicological activity of bisphenol A (BPA) structural analogues and functional alternatives. Toxicology 424:152235

Ramirez V, Galvez-Ontiveros Y, Porras-Quesada P, Martinez-Gonzalez LJ, Rivas A, Alvarez-Cubero MJ (2021) Metabolic pathways, alterations in miRNAs expression and effects of genetic polymorphisms of bisphenol a analogues: a systematic review. Environ Res 197:111062
Rippka R, Deruelles J, Waterbury JB, Herdman M, Stanier RY (1979) Generic assignments, strain histories and properties of pure cultures of cyanobacteria. J Gen Microbiol 111:1-61

Safi C, Zebib B, Merah O, Pontalier P, Vaca-Gracia C (2014) Morphology, composition, production, processing and applications of Chlorella vulgaris: a review. Renew Sustain Energy Rev 35:265-278

Sauer P, Svecova H, Grabicova K, Gonul Aydin F, Mackulak T, Kodes V, Blytt LD, Henninge LB, Grabic R, Kocour Kroupova H (2021) Bisphenols emerging in Norwegian and Czech aquatic environments show transthyretin binding potency and other less-studied endocrine-disrupting activities. Sci Total Environ 751:141801

Seoane M, Cid A, Esperanza M (2021) Toxicity of bisphenol A on marine microalgae: single- and multispecies bioassays based on equivalent initial cell biovolume. Sci Total Environ 767:144363

Shao XL, Ma J, Wen G (2008) Investigation of endocrine disrupting chemicals in a drinking water work located in Songhua River basin. Huan Jing Ke Xue 29:2723-2728

Siracusa JS, Yin L, Measel E, Liang S, Yu X (2018) Effects of bisphenol A and its analogs on reproductive health: a mini review. Reprod Toxicol 79:96-123

Staples CA, Dorn PB, Klecka GM, O'Block ST, Harris LR (1998) A review of the environmental fate, effects, and exposures of bisphenol A. Chemosphere 36:2149-2173

Takeda H (1995) Cell wall sugars of some Scenedesmus species. Phytochemistry 42:673-675

Tisler T, Krel A, Gerzelj U, Erjavec B, Dolenc MS, Pintar A (2016) Hazard identification and risk characterization of bisphenols A, F and AF to aquatic organisms. Environ Pollut 212:472-479

Usman A, Ikhlas S, Ahmad M (2019) Occurrence, toxicity and endocrine disrupting potential of Bisphenol-B and Bisphenol-F: a mini-review. Toxicol Lett 312:222-227

Wang H, Liu ZH, Tang Z, Zhang J, Yin H, Dang Z, Wu PX, Liu Y (2020) Bisphenol analogues in Chinese bottled water: quantification and potential risk analysis. Sci Total Environ 713:136583

Wang Q, Chen M, Shan G, Chen P, Cui S, Yi S, Zhu L (2017a) Bioaccumulation and biomagnification of emerging bisphenol analogues in aquatic organisms from Taihu Lake, China. Sci Total Environ 598:814-820

Wang R, Diao P, Chen Q, Wu H, Xu N, Duan S (2017b) Identification of novel pathways for biodegradation of bisphenol A by the green alga Desmodesmus sp.WR1, combined with mechanistic analysis at the transcriptome level. Chem Eng J 321:424-431

Wang T, Xu F, Song L, Li J, Wang Q (2021) Bisphenol A exposure prenatally delays bone development and bone mass accumulation in female rat offspring via the ER $\beta / \mathrm{HDAC} 5 / \mathrm{TGF} \beta$ signaling pathway. Toxicology 458:152830

Xiang R, Shi J, Yu Y, Zhang H, Dong C, Yang Y, Wu Z (2018) The effect of bisphenol A on growth, morphology, lipid peroxidation, antioxidant enzyme activity, and PS II in Cylindrospermopsis raciborskii and Scenedesmus quadricauda. Arch Environ Contam Toxicol 74:515-526

Xiong JQ, Kurade MB, Abou-Shanab RA, Ji MK, Choi J, Kim JO, Jeon BH (2016) Biodegradation of carbamazepine using freshwater microalgae Chlamydomonas mexicana and Scenedesmus obliquus and the determination of its metabolic fate. Bioresour Technol 205:183-190

Yamazaki E, Yamashita N, Taniyasu S, Lam J, Lam PK, Moon HB, Jeong Y, Kannan P, Achyuthan H, Munuswamy N, Kannan K (2015) Bisphenol A and other bisphenol analogues including BPS and BPF in surface water samples from Japan, China, Korea and India. Ecotoxicol Environ Saf 122:565-572

Zhang Q (2008) Hormesis and adaptive cellular control systems. Dose Response 6:196-208 
Zhang Y, Shen G, Yu Y, Zhu H (2009) The hermetic effect of cadmium of the activity of antioxidant enzymes in the earthworm Eisenia fetida. Environ Pollut 157:3064-3068

Zhang T, Xue J, Gao CZ, Qiu RL, Li YX, Li X, Huang MZ, Kannan K (2016) Urinary Concentrations of bisphenols and their association with biomarkers of oxidative stress in people living near E-waste recycling facilities in China. Environ Sci Technol 50:4045-4053

Zhang W, Xiong B, Sun WF, An S, Lin KF, Guo MJ, Cui XH (2014) Acute and chronic toxic effects of bisphenol A on Chlorella pyrenoidosa and Scenedesmus obliquus. Environ Toxicol 29:714-722

Zhao X, Qiu W, Zheng Y, Xiong J, Gao C, Hu S (2019) Occurrence, distribution, bioaccumulation, and ecological risk of bisphenol analogues, parabens and their metabolites in the Pearl River Estuary, South China. Ecotoxicol Environ Saf 180:43-52

Zhu J, Tan X, Hafid HS, Wakisaka M (2021) Enhancement of biomass yield and lipid accumulation of freshwater microalga Euglena gracilis by phenolic compounds from basic structures of lignin. Bioresour Technol 321:124441

Publisher's note Springer Nature remains neutral with regard to jurisdictional claims in published maps and institutional affiliations. 